\title{
TWEE KRIJGSTOCHTEN UIT DEN INDISCHEN ARCHIPEL TEGEN CEILON.
}

DOOR

Dr. H. KERN.

De Singhaleesche Kronieken maken gewag van twee invallen die de bewoners van Ceilon te verduren hadden onder de regeering van Parākrama-bāhu III (1266-1301), van zekeren vorst Candrabhānu, die het bevel voerde over een leger van Jāwaka's ' . Het woord jāwaka beteekent "iemand uit Java", doch men weet dat de naam Java niet zelden ook op Sumatra wordt toegepast, zoodat wij zonder verdere gegevens niet kunnen uitmaken of Candrabhānu een Javaansch dan wel een Sumatraansch vorst was. In de "History of Ceylon" door W. Knighton, blz. 156 wordt van den eersten inval in 1278 op de volgende wijze gesproken:

"In the eleventh year of this prince's (d. i. Parākrama-bāḥu III) reign, a large army of Malays, under Chundrachano, made their appearance to invade the island. Fortunately for Ceylon, the army which the king had been but recently employing against the Malabars was still enrolled. The king, having previously despatched a small detachment to harass them on their march, advanced with promptitude with all his forces. The two wings of his army, which consisted of his cavalry and elephants, were headed by his nephew, Weerabahu, and his brother, Buwaneko Chako, he himself leading on the centre in person. A dreadful conflict ensued, in which the Malays were so utterly destroyed, that a native historian compares their defeat to "a wood of reeds crushed and uprooted by the gust of a tempest."

Men ziet, de Engelsche schrijver noemt de invallers "Maleiers." Aangezien hij, zooals uit de verhaspeling der eigennamen, en trouwens uit zijn geheele boek blijkt, niet in staat was de bronnen

1 De $j$ uit te spreken als de Engelsche $j$, bijv. in $\mathrm{John}$; de $c$ als $t s j$. 
in 't oorspronkelijke te lezen, moet hij den term "Maleier" aan eene of andere vertaling te danken hebben. Wat Lassen geeft in zijne "Indische Alterthumskunde", IV , 345, is onbruikbaar, en zijn bron, Upham's zoogenaamde vertaling der kronieken, is van de troebelste. Uit Valentijn's verward overzicht van de geschiedenis van Ceilon in D. V, 1 van zijn werk, wordt over 't onderwerp dat ons hier bezig houdt in 't geheel niets gezegd. Daarom zullen we hier twee stukken uit de kroniek Mahāwamsa, die de invallen der Jāwaka's beschrijven, in Pāli-tekst en vertaling mededeelen. De door ons gebruikte tekst is de door H. Sumangala en Don Andris de Silva Batuwantudawa bezorgde uitgave van genoemde kroniek, tweede gedeelte, van hoofdstuk XXXVII tot CI, gedrukt te Colombo 1877.

Het eerste stuk, hoofdst. LXXXIII, vs. $36-48$, luidt als volgt: athekādasame wasse sampatte tassa rājino | tadā Jāwakarājeko Candabhānūti wissuto \| "wayam pi Sogatā ewa" iti māyam widhāya so | saddhim Jāwakasenāya Kakkhalāya samotari \| sabbe te Jāwakā yodhā sabbatitthāwagāhino wisadiddhehi bānehi ghorasappanibhehi ye \| diț̣he-diț̣the jane duțțhā bādhamānā nirantaram kodhā sandhāwamānā tu sabbam Lañkam vināsayum || pāwakāsanividdhastam ṭhānami nîrāsanì wiya | Māghādibādhitain Lan̄kam Jāwakā puna bādhayum ॥ bhāgineyyam tadā wìram Wìrabāhumahìpatim | rājā Jāwakayuddhāya saddhị̣ yodhehi pesayi ॥ ghoraw esadharo Wîrabāhu-rāhu bhayañkaro | niruddhi Candabhānum tam bhusam raṇanabhangane \| sa Sîhalabhațe wìre tattha-tattha niyojiya | saddhim Jāwakayodhehi yuddham kattum samārabhi || yuddhe Jāwakayodhehi yantamutte laghum-laghum | wisadiddhamukhe bāne bahudhābhimukhāhate ॥ lakkhawedì mahāyodhā Sìhalā ye dhanuddharā | tikkhasallehi bhallehi khaṇạaso khaṇdayimsu te \| Rāmo' wa samaram gantwā Wìrabāhumahîpati | rakkhase wiya māresi lahu Jāwakayodhake || mahāwegadharo Wîrabāhuwerambamanthano | Jāwakārimahāraññam paribhañjì punappunami || ewam ewa[m] sa yujjhitwā palāpetwāna Jāwake | paccatthirahitam kāsi sabbam Lañkāmahìtalam \| 
D. i. "In 't elfde jaar vạn dien vorst (Parākramabāhu III) was het dat zekere Javaansche ${ }^{1}$ koning, Candrabhānu geheeten, met een leger van Javanen te Kakkhalā landde na listig voorgegeven te hebben: "Ook wij zijn Buddhisten." De Javaansche krijgers, die alle van vergiftigde pijlen, aan gruwelijke slangen gelijk, voorzien waren, maakten zich van alle rivierovergangen meester, plaagden boosaardig onophoudelijk een ieder die hun in 't gezicht kwam, en richtten overal woedend rondloopende geheel Lankā (Ceilon) ten gronde. Lañkā, dat door Māgha ${ }^{2}$ en anderen geplaagd was, werd nu weder door de Javanen gekweld, gelijk eene plaats die na door bliksemvuur geteisterd te zijn, te lijden heeft van een waterramp. Toen zond de koning zijnen heldhaftigen neef, den regent Wîrabāhu met troepen om de Javanen te bestrijden. Wìrabāhu, die, ontzagwekkend uitgedost, vrees inboezemde, stuitte Candrabhānu met kracht op het slagveld, als ware hij de schrikverwekkende (demon) Rāhu, die maan en zon $^{3}$ benauwt in 't hemelruim. Na de dappere Singhaleesche soldaten op verschillende plaatsen geposteerd te hebben, opende hij (Wîrabāhu) tegen de Javaansche krijgers het gevecht. Deze laatsten schoten met groote gezwindheid vergiftigde pijlen van hun bogen af, die echter overal door de scherpschutters onder de voortreffelijke Singhaleesche krijgslieden met hun scherpgepunte pijlen in de vaart werden gestuit en stuk geschoten. De regent Wîrabāhu doodde weldra de Javaansche krijgers, gelijk Rāma, ten strijde getogen, de Reuzen. Met groote onstuimigheid bracht Wìrabāhu den Javaanschen vijand herhaaldelijk de nederlaag toe, gelijk een hevige orkaan verwoesting aanricht in het wilde woud. $\mathrm{Na}$ aldus gestreden en de Javanen op de vlucht gedreven te hebben, bevrijdde hij den ganschen bodem van Lankā van vijanden."

Eenige jaren later ondernam Candrabhānu, die over de geleden nederlaag blijkbaar niet voor goed afgeschrikt was, opnieuw een tocht tegen het eiland, en ditmaal na zijn leger met hulptroepen uit Zuidindië versterkt te hebben. Bij Knighton, blz. 158, lezen wij hieromtrent het volgende: "In the midst of these energetie

$1 \mathrm{~W}_{\mathrm{ij}}$ bezigen dezen term zonder te beslissen of daarmeê niet een Sumatraan kan bedoeld wezen.

'Māgha was een Zuidindisch veroveraar, die in 1214 't eiland aan zich onderwierp en tot 1235 daar als dwingeland regeerde.

3 Eene woordspeling op den naam Candrabhānu, welks twee bestanddeelen „maan" en „zon" beteekenen. 
TWEE KRIJGSTOCHTEN UIT DEN IND. ARCHIPEL TEGEN CEILON. 243

labours, Prackrama was interrupted by the second invasion of Chundrachano, who now came, assisted by a large force of Pandians and Solleans, but who was a second time defeated and obliged to fly with precipitation." De Mahāwamisa geeft het verhaal van deze gebeurtenis in hoofdst. LXXXVIII, vs. 62-75. De tekst luidt:

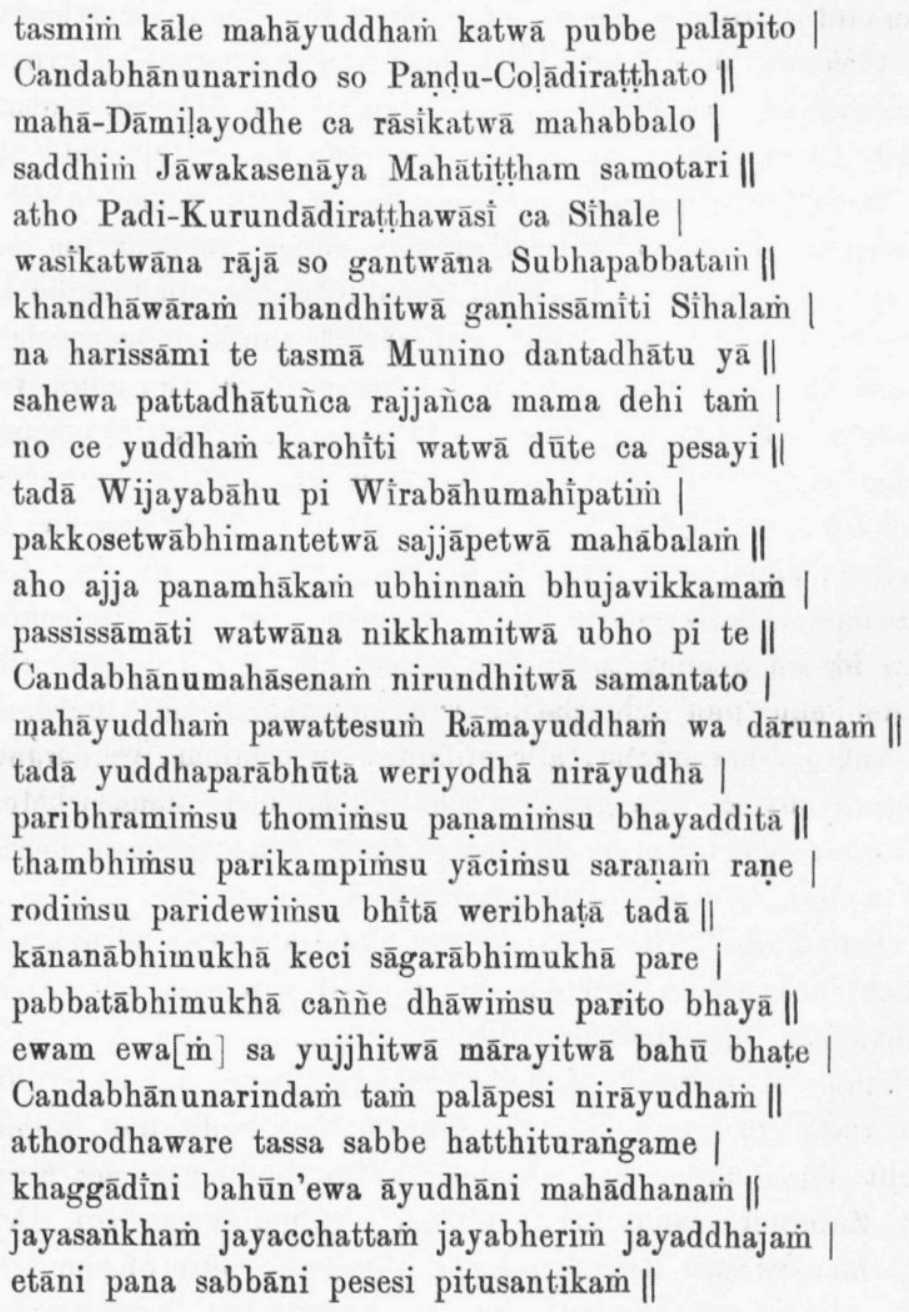

D. i. "Het was te dier tijd dat de koning Candrabhānu, die vroeger na een grooten slag op de vlucht was gejaagd, na eene groote krijgsmacht uit de rijken Pāṇ̣ya, Cọ̣a enz., alsook Tamilsche soldaten verzameld te hebben, met een leger van Javanen te Mahātìrtha landde. Daarop onderwierp genoemde koning de 
Singhaleezen die in de districten Padi, Kurunda ' enz. woonden en trok naar den berg Subha. Na daar zijn hoofdkwartier gevestigd te hebben, zond hij afgevaardigden (naar den koning van Ceilon) met de woorden: "Ik wil Ceilon in bezit nemen. Daarom zal ik u de tandreliek van den Wijze (Buddha) niet ontrooven. Geef mij die, benevens de bedelpotreliek en de heerschappij. Anders, maak u op ten strijde." Toen liet Wijayabāhu (de rijksbestierder) den regent Wîrabāhu roepen, hield raad en liet eene groote krijgsmacht uitrusten. "Welaan! van daag dan zullen wij zien hoe krachtig ons beider armen zijn", zeide Wijayabāhu, en daarop trokken beide uit. $\mathrm{Na}$ het groote leger van Candrabhānu van alle kanten ingesloten te hebben, leverden zij een grooten slag, vreeselijk als de strijd van Rāma (tegen de Reuzen). Toen leden de vijandelijke krijgers de nederlaag in den strijd; met verlies van hun wapens doolden zij rond, gaven zich over en onderwierpen zich, van angst vervuld; zij waren verstijfd van schrik, sidderden, smeekten om lijfsbehoud in den strijd; zij weenden, weeklaagden toen in hun angst, de vijandelijke soldaten. Sommigen vluchtten in de richting van de bosschen, anderen in die van de zee, wederom anderen liepen van vrees her- en derwaarts in alle richtingen. $\mathrm{Na}$ aldus vechtenderhand veel soldaten gedood te hebben, dreef hij (Wirrabāhu) dien koning Candrabhānu met achterlating van wapenen op de vlucht. Daarop makte hij diens harem, alle olifanten en paarden, veel wapentuig, zwaarden enz. en een grooten schat gelds, den staatsieschelphoorn, den staatsiezonnescherm, de staatsiepauk, den staatsiestandaard buit, en zond die alle aan zijnen vader."

Zoo dan luidt het verhaal van Candrabhānu's mislukte krijgstochten naar Ceilon volgens den dichter van den Mahāwamisa. De voornaamste bijzonderheden die wij omtrent de Jāwaka's vernemen, zijn: dat zij gebruik maken van vergiftigde pijlen, en dat hun vorst verklaart een belijder te zijn van 't Buddhisme. Wel is waar schrijft de dichter der kroniek 't laatste toe aan geveinsdheid, doch daarvoor schijnt geen voldoende grond te bestaan. Dat Candrabhānu op zijn tweeden tocht Tamilsche hulptroepen in dienst heeft, die steeds getoond hadden verbitterde tegenstanders der Buddhisten te wezen, bewijst ook niet veel. Doch, hij zij een overtuigd Buddhist geweest of niet, in geen van beide gevallen vinden wij een gegeven om te beslissen of met Jāwaka's Javanen

1 Deze twee districten worden ook vermeld in LXXXII, vs. 16. 
in engeren zin dan wel Sumatranen bedoeld zijn. De vermelding van vergiftigde pijlen bewijst alleen dat de vreemdelingen onder aanvoering van Candrabhānu uit den Indischen Archipel afkomstig waren, want op 't Indische vasteland was 't gebruik van zulke pijlen in den oorlog verboden. De naam Candrabhānu is zuiver Sanskrit, doch zoowel op Sumatra als op Java droegen de vorsten niet zelden zulke namen.

Van de geschiedenis van Java in de laatste helft der $13^{\mathrm{e}}$ eeuw is ons betrekkelijk veel bekend, zoowel uit inheemsche als uit Chineesche bronnen. Van een Javaanschen vorst Candrabhānu wordt, voor zoover mij bekend is, nergens gewag gemakt. Van den toestand op Sumatra omstreeks dien tijd weten wij nagenoeg niets. Alleen kunnen wij uit verschillende gegevens opmaken dat in verschillende streken van 't eiland de leer van Buddha ingang had gevonden.

Uit den naam Jāwaka valt, zooals reeds opgemerkt is, niets met zekerheid af te leiden. Het oorspronkelijke Sanskritwoord is ook in het Tamil overgegaan, cnder den vorm S'āwagĕr (gespeld Cāwakar), in 't meervoud, en S'āwagam. Het eerste wordt in Winslow's "Tamil and English Dictionary", kol. 441, vertaald met "Javanese"; het tweede, kol. 754, met "Javanese, Malacca", waaruit eene wanhopige verwarring blijkt tusschen Javaansch en Maleisch. Niet beter is wat bij S' à wa s'a m, kol. 441, opgegeven wordt: "One of the eighteen languages - the Malay language of Java"! !

Wij behoeven de hoop niet op te geven dat de naam van Candrabhānu eenmaal op Sumatra of Java zal ontdekt worden, maar zoolang dat niet geschied is, moeten wij de vraag uit welke streek de tocht naar Ceilon ondernomen werd onbeslist laten. Alles te zamen genomen, zou ik geneigd wezen te veronderstellen dat de tocht van uit Sumatra ondernomen werd. Zooveel is echter zeker, dat Candrabhānu geen Mohammedaan was. 